Supplement of Hydrol. Earth Syst. Sci., 22, 3863-3882, 2018

https://doi.org/10.5194/hess-22-3863-2018-supplement

(C) Author(s) 2018. This work is distributed under

the Creative Commons Attribution 4.0 License.

(c) (1)

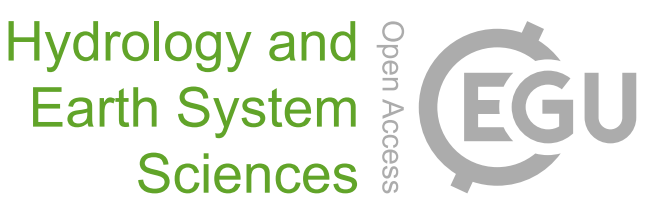

Supplement of

\title{
Assimilation of river discharge in a land surface model to improve estimates of the continental water cycles
}

Fuxing Wang et al.

Correspondence to: Fuxing Wang (fuxing.wang@lmd.jussieu.fr)

The copyright of individual parts of the supplement might differ from the CC BY 4.0 License. 
(a) dP,WFDEIGPCC-IBO2

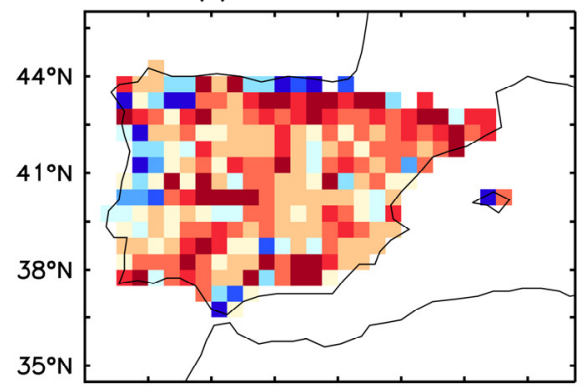

(d) Ratio of P.WFDEIGPCC/IB02

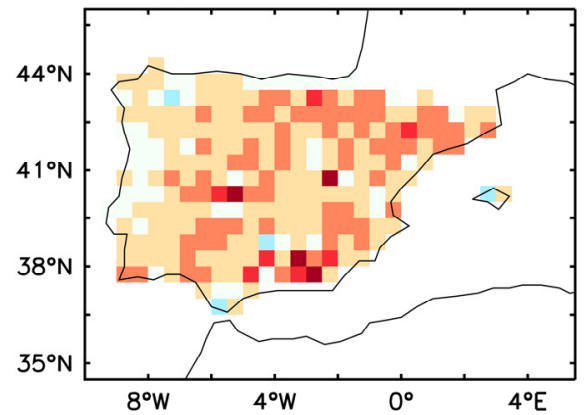

(b) dP,WFDEICRU-IBO2

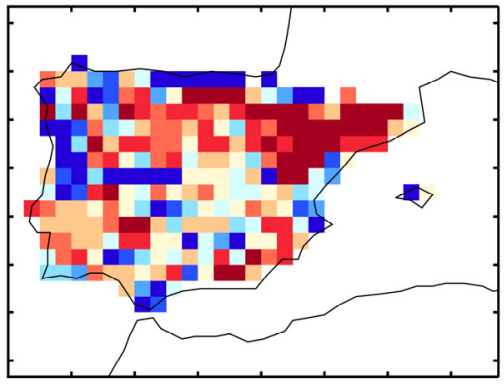

(e) Ratio of P.WFDEICRU/IB02

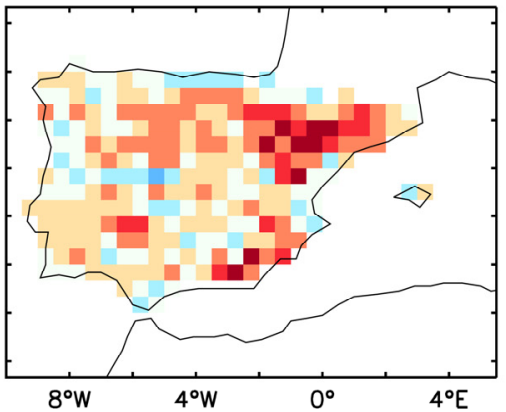

(c) dP,CRUNNCEP-IBO2

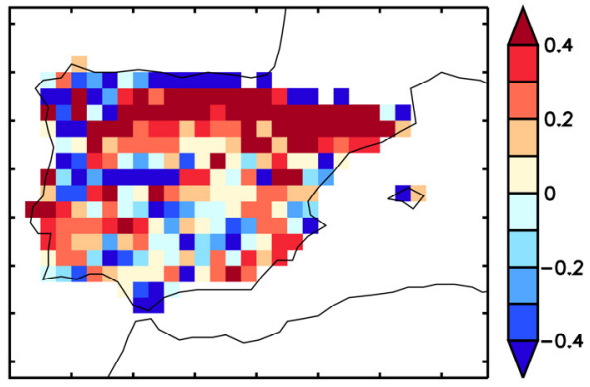

(f) Ratio of P.CRUNNCEP/IBO2

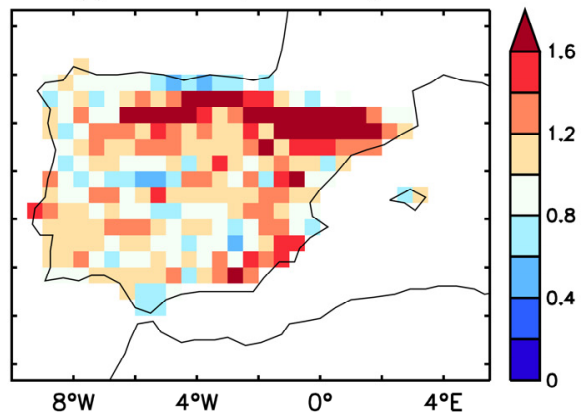

Figure S1. Comparison of precipitation $(P$, in $\mathrm{mm} / \mathrm{d})$ between IB02 and that used in the assimilation (a and d: WFDEI-GPCC; $b$ and e: WFDEI-CRU; $c$ and f: CRUNCEP) averaged from 1980 to 1989: $1^{\text {st }}$ row for difference; $2^{\text {nd }}$ row for ratio. 